\title{
The Effects of Continuous Press Speed and Conditioning Time on the Particleboard Properties at Industrial Scale
}

\begin{abstract}
Osman Çamlıbel ${ }^{\mathrm{a}}$ and Murat Aydın ${ }^{\mathrm{b}, *}$
Effects of continuous press speed (580 and $600 \mathrm{~mm} / \mathrm{s}$ ) and conditioning time $(0$ and $72 \mathrm{~h})$ on some physical and mechanical properties and formaldehyde content of particleboards were investigated. The $18 \mathrm{~mm}$ thick boards were manufactured using urea-formaldehyde, with a $50 \%$ pine, $40 \%$ oak wood, and $10 \%$ poplar biomass mixture of the wood materials. According to the results of the unconditioned samples, the density, modulus of rupture (MOR), moisture content (MC), thickness swelling (TS), and water absorption (WA) were increased $0.8 \%, 4.4 \%$, $0.4 \%, 4.4 \%$, and $5.5 \%$ when press speed increased from 580 to $600 \mathrm{~mm} / \mathrm{s}$, while thickness, modulus of elasticity (MOE), internal bond (IB), surface soundness (SS), and free formaldehyde (FF) were decreased $0.3 \%, 4.9 \%$, $2.4 \%, 10.6 \%$, and $21.1 \%$, respectively. On the contrary to the results of unconditioned samples, MOE and SS were increased $1 \%$ and $1.4 \%$, respectively, and WA was decreased $3.5 \%$ with the increase in press speed when samples were conditioned for $72 \mathrm{~h}$. Free formaldehyde content was the most prominent parameter influenced by the increase in press speed both for the unconditioned and $72 \mathrm{~h}$ conditioned samples.
\end{abstract}

DOI: 10.15376/biores.17.1.159-176

Keywords: Continuous press speed; Conditioning time; Particleboard; Physical and mechanical properties; Formaldehyde content

Contact information: a: Department of Interior Design Kırlkkale Vocational School, Kırlkkale University, Kırlkkale, Turkey; b: Department of Machine, Keçiborlu Vocational School, Isparta University of Applied Sciences, Isparta, Turkey; *Corresponding author: murataydin@isparta.edu.tr

\section{INTRODUCTION}

Particleboards (PBs) are engineered wood-based panel materials that are widely used in construction concerning painting, veneering, or other surface coatings. Due to its competitive price and remarkable physical and strength properties, PB is one of the most commonly used panel materials in the furniture or construction industry. On the other hand, formaldehyde release with the lapse of time in use is a safety burden even if they are produced in compliance with the standards.

\section{Literature Background}

When literature is reviewed, it becomes apparent that the essential investigation variables are pressing parameters (type, time, pressure, speed, etc.), material (standalone or a mixture of wood species, resin type and ratio in the core and surface layers, agricultural materials or wastes, cotton stalks, etc.), and modification agents (minerals, nanowollastonite, nanosilver, etc.). Changes in physical (density, thickness, moisture contentMC, thickness swelling-TS, water absorption-WA, surface roughness-SR, etc.) and 
mechanical (modulus of elasticity-MOE, modulus of rupture-MOR, internal bond-IB, surface soundness-SS, screw holding resistance-SHR, etc.) properties, and formaldehyde emission (FE) are commonly evaluated dependent variables in the studies concern with particleboard production.

\section{Effects of press type and parameters, wood species, and resin}

The performance of the pressing process depends on time, pressure, temperature, resin type, etc. for discontinuous systems such as hydraulic plate press. In addition to these parameters, speed is one of the essential factors that have influences on the press time, temperature, pressure, resin curing, etc. for continuous press systems. Such combined influences for continuous press were evaluated in the following limited studies: Candan et al. (2012) evaluated the effect of continuous press speed (CPS) $\left(6.9\right.$ and $7.4 \mathrm{~m} / \mathrm{min}^{1}$ speed, and $220^{\circ} \mathrm{C}$ temperature) on layer TS of $18 \mathrm{~mm}$ thick medium-density fiberboard (MDF) produced using a chip mixture (70:30 beech and birch wood, respectively). It was stated that TS ( 2 and $24 \mathrm{~h}$ ) values decreased when CPS increased, and resin content (RC) and moisture content (MC) and CPS could be effectively used to obtain the desired performance. Çamlibel (2020a) evaluated the effect of UF utilization percentages on the properties of $18 \mathrm{~mm}$ thick $725 \mathrm{~kg} / \mathrm{m}^{3}$ density fiberboard produced using the birch and continuous press. However, no production parameters for pressing were reported. Çamlibel (2020b) evaluated the effect of speed $(200,230,240$, and $250 \mathrm{~mm} / \mathrm{s})$, temperature (185, 210,220 , and $\left.230^{\circ} \mathrm{C}\right)$, and time $(150,160,170$ and $200 \mathrm{~s})$ of press application on the density, WA, TS, and free formaldehyde (FF) of the PB produced using continuous press and 40:30:20:10 mixture of Scots pine (Pinus sylvestris L.), sessile oak (Quercus petraea (Matt.) Liebl.), poplar (Populus alba L.), and sawdust. The author stated that further increases than optimum set-up values in press time and temperature were responsible for adverse effects on the PB properties. Ciobanu et al. (2014) evaluated the effects of CPS (500 to $1190 \mathrm{~mm} / \mathrm{s}$ ), temperature $\left(190\right.$ to $250{ }^{\circ} \mathrm{C}$ ), and pressure $(1.5$ to $5 \mathrm{MPa}$ ) on the properties of oriented strand boards (OSB type 3) produced using melamine-ureaformaldehyde (MUF) and polymeric diphenylmethane diisocyanate (PMDI) adhesives, and the mixture of soft- and hardwood species. The authors stated that physical and mechanical properties are strictly related to speed and press factor, and low speed increased all the mechanic properties.

Onuorah (2001) evaluated the effect of pressure and time for fast (4.83 and 3.79 $\mathrm{MPa}$ for $1.5 \mathrm{~min}$ ) and slow (3.45 and $2.76 \mathrm{MPa}$ for $3 \mathrm{~min}$ ) closing application in hot pressing $\left(350{ }^{\circ} \mathrm{C}\right)$ on the properties of $13 \mathrm{~mm}$ thick PBs produced using pine and maple furnishes. Miyamoto et al. (2002) evaluated the effect of press closing time (PCT) (4, 10 to $900 \mathrm{~s}$ correspond to 115,117 to $105^{\circ} \mathrm{C}$ temperature) on MOR, MOE, and IB of $10 \mathrm{~mm}$ thick PB produced using Hinoki (Chamaecyparis obtusa Endl.). The authors stated that "The bending properties decreased with increasing PCT because of the low density and the pre-cured layer in the surface regions of the board," and "TS seemed to increase with increasing PCT."

Warmbier et al. (2014) evaluated the effects of temperature $\left(180\right.$ and $\left.200^{\circ} \mathrm{C}\right)$, press time (4 and $6 \mathrm{~min}$ ), and shelling ratio (0.3 and 0.4) on the MOE, MOR, IB, and SHR of 16 $\mathrm{mm}$ thick $\mathrm{PB}$ produced using willow Salix viminalis and pine particles for the core and face layers, respectively. The authors stated that $180{ }^{\circ} \mathrm{C}$ and 4 min press application was not enough for the adequate cure of adhesive. Iswanto et al. (2014) evaluated the effects of pressing temperature $\left(110,120\right.$, and $130{ }^{\circ} \mathrm{C}$ ) and time ( 8 and $\left.10 \mathrm{~min}\right)$ on the quality of the PB treated by immersing in $1 \%$ acetic acid solution, and stated that higher pressing 
temperature and time provided the highest physical and mechanical properties. Nitu et al. (2020) evaluated the effect of press temperature and time (160 to $240{ }^{\circ} \mathrm{C}$ and 4 to $10 \mathrm{~min}$ ), varying mixtures $(0,30,40,50,100 \%)$ of fine and coarse particles on the properties of 6 $\mathrm{mm}$ thick $900 \mathrm{~kg} / \mathrm{m}^{3}$ density jute stick binderless PB. The authors reported that $220{ }^{\circ} \mathrm{C}$ and 6 min were the optimum pressing conditions. Saad et al. (2019) evaluated the utilization of empty fruit bunches (EFB) and the Merkusii pine bark for $10 \mathrm{~mm}$ thick PB production by optimizing the composition (90:10, 85:15, 80:20, 75:25, and 70:30), temperature (150, $160,170,180$ and $\left.190{ }^{\circ} \mathrm{C}\right)$, and time $(10,15,20,25$, and $30 \mathrm{~min})$ variables. However, the authors stated that PB did not meet the requirements of density, MC, and MOR. Widyorini (2020) evaluated the effect of pressing temperature $\left(160,180\right.$, and $\left.200{ }^{\circ} \mathrm{C}\right)$ and time $(5 \mathrm{~min}$ +1 min breathe $+5 \mathrm{~min}$ ) on the properties of PB produced using bamboo petung particles, and the mixture of sucrose and ammonium dihydrogen phosphate (100:0, 95:5, 90:10, $85: 15$, and $80: 20 \mathrm{wt} \%$ ) as adhesive. The author stated that the combined effect of temperature and the adhesive ratio was found to be significant for TS, WA, SR, MOR, MOE, IB, and SHR properties.

Nemli (2002) evaluated the effect of press temperature $\left(180\right.$ and $\left.200{ }^{\circ} \mathrm{C}\right)$, time $(135$ and $150 \mathrm{~s}$ ), pressure (3.19 and $3.4 \mathrm{MPa})$, and adhesive ratio in outer and core layers (9.5:8.5, 11:9, and 9:7 dry wt) on TS, MOR, IB, and FE of PB produced using 50:40:10 mixture of beech, pine and poplar chips, and E1 class UF adhesive. The author stated that an increase in the temperature, time, and pressure in the pressing process improves the technological properties of PBs. Heebink et al. (1972) evaluated the effect of press temperature $\left(163,191,218\right.$, and $\left.246^{\circ} \mathrm{C}\right)$, time $(15,30,60$, and $120 \mathrm{~s})$, species (Douglas fir, aspen, and southern pine), thickness $(6.35,12.7,19$ and $25.4 \mathrm{~mm})$, density $(481,641,801$, and $\left.961 \mathrm{~kg} / \mathrm{m}^{3}\right), \mathrm{MC}(8,10,12$, and 14\%), and resin type (urea-formaldehyde (UF), phenolformaldehyde (PF), and melamine-formaldehyde (MF)) on the properties of PB to provide maximum values at minimum pressing time. The authors stated that optimum timetemperature combination provides a proper cure of binder and loss of sufficient moisture to prevent steam blisters. However, reduction in pressing time caused proportional decreases in board strength. Li et al. (2010) stated that for the exact cure of the resin, extended press time (350 s; $40 \mathrm{~s}$ closing, $260 \mathrm{~s}$ at the target thickness, and $50 \mathrm{~s}$ opening) was used for the production of PB using different geometries of rice straws. Ramezanpoor Maraghi et al. (2018) evaluated the effect of pressing temperature $\left(160\right.$ and $\left.170^{\circ} \mathrm{C}\right)$, density $\left(650,700\right.$, and $\left.750 \mathrm{~kg} / \mathrm{m}^{3}\right)$, and RC (9 and $11 \%$ ) on the properties of $16 \mathrm{~mm}$ thick PB produced using poplar wood slab, citrus branches and twigs of beech, and UF adhesive. The authors stated that temperature increases provided slight increases in WA and MOE, while there were decreases in IB and TS. Barragàn-Lucas et al. (2019) determined the effects of pressing temperature $\left(150\right.$ and $170{ }^{\circ} \mathrm{C}$ ) and $\mathrm{RC}(15$ and $35 \%$, and 25 and $45 \%$ coarse and fine fibers, respectively) on the properties of the PB made of banana pseudostem. The authors stated that temperature negatively affected the density and TS, and positively affected the FF, WA, MOE, and MOR. Yel et al. (2020) evaluated the effect of press temperature $\left(20,30,40,50,60,70\right.$, and $\left.80^{\circ} \mathrm{C}\right)$ on cement-bonded PB produced with spruce and poplar wood species, and stated that exceeding the $60{ }^{\circ} \mathrm{C}$ causes reverse effects on the properties. Ferrandez-Villena et al. (2020) evaluated the effects of pressing time (7, $7+7,15,15+15 \mathrm{~min}$ ), pressing cycle (two cycles of $7+7$ and $15+15 \mathrm{~min}$ ), and particle size on the the properties of PB produced using Arundo donax L. The authors stated that mechanical properties are increased with the increase in time. On the contrary, a shorter pressing time caused better TS and WA values. The 0.25 to $1 \mathrm{~mm}$ particle sizes provided better mechanical properties. 
Nemli et al. (2004) evaluated the effect of press type (continuous and discontinuous hydraulic plate) on MOE, MOR, SHR, Tensile Strength (TS), $18 \mathrm{~mm}$ thick $680 \mathrm{~kg} / \mathrm{m}^{3}$ density PB produced using 50:40:10 mixture of beech, pine, and poplar species, respectively. According to results, MOR, MOE, SHR (perpendicular to the plane), and TS were found to be lower than the values obtained using discontinues press. On the contrary, TS (perpendicular to the plane) and SHR (perpendicular to the edge) were found to be higher than the values obtained using a discontinuous press. Differences in core layer furnishing, and press temperature, and pressure were assumed as factors that caused value deviations between continuous and discontinue presses. Nemli and Demirel (2006) determined MOR, MOE, IB, TS, and SR of $18 \mathrm{~mm}$ thick PB produced using continuous $\left(220{ }^{\circ} \mathrm{C}\right.$ and $\left.155 \mathrm{~s}\right)$ and one-opening presses, and beech (Fagus orientalis Lipsky.), poplar (Populus tremula L.), pine (Pinus sylvestris L.), and oak (Quercus cerris L.) species. The authors stated that TS of the PB was influenced by press type, and continuous press application provided lower TS values than on-opening. On the other hand, MOR and MOE of PB produced using a one-opening press provided higher values. Significant IB values for the PB were obtained when the continuous press was used. Güler and Sancar (2016) stated that boards produced using discontinuous (one-layer) press provided higher MOR and IB, and lower TS ( $2 \mathrm{~h})$ values than continuous press. Furthermore, one-layer discontinuous press can be chosen to produce the better quality board, but when production capacity is taken into consideration continuous presses come to forefront.

\section{Effects of modification agents}

Mantanis et al. (2018) reported that fire retardant agents for PB are used in solid form and mixed with the chips in the blending phase. Up to $30 \%$ slower press speed is needed in this type of production. Lehmann et al. (1973) evaluated the effect of variables (catalysts used in gluing, and non-catalyzed resin binders) on the physical and mechanical properties of $\mathrm{PB}$ for the determination of minimum pressing time for production. The authors stated that heat transfer is the primary issue that varies with thickness, press temperature, closing rate, and mat moisture distribution. The nano-wollastonite addition to improve thermal conductivity, physicals and mechanical properties of the boards was evaluated by Taghiyari and Nouri (2016), and the authors reported that $15 \%$ utilization can be recommended to advance the properties. Taghiyari and Norton (2014) reported that hot press duration and nano-silver addition have significant effects on the hardness, WA, and TS properties of fiberboard. Yildirım and Candan (2021) stated that nanocellulose and boric acid have significant influences on physical and mechanical properties of PB. Leng et al. (2017) stated that density and cellulose nanofibrils addition (10, 15, and 20\% dry wt) have significant positive influences on MOE and MOR, while particle size has slight influence. İstek et al. (2018) reported the formaldehyde-related problems and reduction methods for the FF or FE of wood-based boards. Çamlıbel and Yilmaz Aydın (2020) reported that zeolite utilization reduces the ability of making bonds between fibers that is assumed as one of the reasons for higher TS and WA values. However, the $1.5 \%$ zeolite addition provided decreases in FE. Çolak et al. (2015) stated that addition of tannin and chitosan $(2 \%)$ decreased and increased the FE of PB, respectively. Furthermore, maximum FE was observed when both tannin and chitosan added. Nemli and Çolakoğlu (2005) reported that using mimosa bark on PB production caused the lowest mechanical properties, and FE and TS of PB were significantly decreased with bark usage. Lum et al. (2014) reported that FE of PB was reduced when amino compounds were applied in production. Buyuksari et al. (2010) determined FE, and some physical and mechanical 
properties of $10 \mathrm{~mm}$ thick $\mathrm{PB}$ produced using mixture of Pinus nigra Arnold var. pallasiana and Fagus orientalis Lipsky woods and cone particles. The authors stated that PB can be produced using cone in a mixture with wood particles and UF adhesive.

\section{Numeric modeling and analysis}

Continuous hot presses (CHP) are one of the main equipment types for fiberboard production (Zhu et al. 2018). Besides the cited study, the following studies present numerical analyses of CHP for fiberboard or PB production. Godbille (2002) provided a two-dimensional numeric model for CHP of PB and determined the effects of parameters on the process. Pereira et al. (2006) developed a three-dimensional model for CHP of MDF and simulated predictions of the model. Thoemen and Humphrey (2003) provided a numerical model that is directly applicable to CHP, due to the provided specific properties for CHP such as "changing mat thickness and steel belt temperatures in the feed direction, and the escape of vapor and air through the horizontal surfaces immediately in front of and behind the press, and the possibility to vary the mat thickness across the width of the press". Lv et al. (2020) suggested a fuzzy failure mode and effects analysis technique combined with defect and failure analysis technique for the quality control of MDF production using CHP.

Apart from the categories already considered, the following studies also dealt with PB. Mirski et al. (2019) evaluated the effects of the three different chipboard structures (microchips, chip-sawdust, and chipboards) on the physical and mechanical properties. Taş and Sevinçli (2015) evaluated the utilization of different mixtures of waste lavender stems and red pine chips, and UF resin. An intensive literature review for the processing parameters and physical, strength, and moisture-related dimensional properties of PB was reported by Kelly (1977). Jasmani et al. (2020) reviewed nano-technology applications for the property (ultraviolet absorption, fire retardancy, mechanical properties, durability, biocide enhancement, etc.) improvements of wood or wood-based products.

As can be seen in the extensive literature review provided above, many studies have reported on the effects of different factors on the properties of PB. However, the effects of CPS and conditioning time (CT) on some physical and mechanical properties and FF of the PB have not been reported before. Also, PBs evaluated in this study were not produced using laboratory-type machines. On the contrary, they were produced using the actual production line of a factory to provide advances on the production process with fulfilling the commercial product requirements. Therefore, this study tried to figure out this issue using two different press speeds and conditioning periods under real production conditions.

\section{EXPERIMENTAL}

\section{Materials}

Wood

Scots pine (Pinus sylvestris L), sessile oak (Quercus petraea (Matt.) Liebl) woods, and waste poplar (Populus alba L.) woods (biomass) were used in this study due to the ease provided in these naturally grown species and physical, mechanical, and chemical properties as well. Scots pine, oak, and poplar raw materials were provided from Bolu, Zonguldak, and Sakarya province of Turkey, respectively. The mixture of 50, 40, and 10\% of the species was prepared for panel production. Invaluable poplar wastes were used to reduce the cost of the boards. 
Adhesive

Urea-formaldehyde adhesive, which was produced by the Kastamonu Glue Plant (Kasatamonu, Turkey) was used in this study, and the properties of the adhesive are presented in Table 1.

Table 1. Properties of the UF Adhesive Used for Panel Production

\begin{tabular}{|c|c|}
\hline Properties & Values \\
\hline Solids content $(\%)$ & $62 \pm 1$ \\
\hline Molar ratio & Surface Layer $(\mathrm{SL}): 0.98$ and Core Layer $(\mathrm{CL}): 1.07$ \\
\hline Density $\left(\mathrm{g} / \mathrm{cm}^{3} @ 20^{\circ} \mathrm{C}\right)$ & 1.227 \\
\hline Viscosity $(250 \mathrm{cP})$ & 20 to $35 \mathrm{~s}$ \\
\hline Gel time $\left(100{ }^{\circ} \mathrm{C}\right)\left(20 \%\left(\mathrm{NH}_{4} \mathrm{Cl}\right)\right.$ & 20 to $45 \mathrm{~s}$ \\
\hline $\mathrm{pH}$ & 7 to 8.5 \\
\hline Free formaldehyde $(\%$ max. $)$ & 0.20 \\
\hline Methylol groups $(\%)$ & 12 to 15 \\
\hline Shelf life (day) & 75 \\
\hline
\end{tabular}

\section{Hardener}

Ammonium chloride $(\mathrm{NH} 4 \mathrm{Cl})$, an organic compound, was used as the hardener agent provided by a private company in Gezbe, Turkey. The $20 \% \mathrm{NH}_{4} \mathrm{Cl}$ solution was used for the catalyst process. The density and $\mathrm{pH}$ of the solution were $0.95 \mathrm{~g} / \mathrm{cm}^{3}$ and 6.5 , respectively.

\section{Paraffin}

Paraffin, in liquid form and dirty white color, was provided by a commercial company (Mercan Chem. Co., Denizli, Turkey). The solid content, pH, viscosity, and density of the paraffin were $60 \%, 9$ to 10,13 to $23 \mathrm{~s}$, and $0.96 \mathrm{~g} / \mathrm{cm}^{3}$, respectively.

\section{Methods}

Board production

Raw wood materials were roughly chipped (Fig. 1-A) using a chipping machine, and chips were separately ensilaged using a band-type conveyor in terms of wood species. Chip mixtures were arranged according to production parameters. Chips for the surface layer (SL) and center layer (CL) were dried up to $2.5 \%$ and 1.5 to $1.75 \%$ MC level using a rotary cylinder dryer. Chips were screened using a three-leveled mechanic vibrating sieve. Pallman type mills were used for sizing the SL and CL, using the standardized chips. The sizes of the SL and CL chips were around 0.12 to 0.26 and 0.3 to $0.47 \mathrm{~mm}$, respectively. Chips were ensilaged in the CL and SL silos according to their dimensions. The $10.8 \%$ and $6 \%$ adhesive solid contents were used for the SL and CL. The volumetric content of the boards for the CL and SL was $65 \%$ and $35 \%$, respectively. Mats were obtained using the adhesive, hardener, and paraffin added chips in the layering station. Mats were pre-pressed for making them ready for the hot press process.

Particleboards were produced using the actual production line of the plant instead of laboratory-type machines. Production parameters of the PBs are presented in Table 2. Two different speeds (580 and $600 \mathrm{~mm} / \mathrm{s}$ ) were used to determine the CPS effect on the board properties. However, there are five different sequential sections of the $\mathrm{CP}$, and the pressure and temperature of these sections were as shown in Table 2. Boards were cooled for around $60 \mathrm{~min}$ to obtain 20 to $25{ }^{\circ} \mathrm{C}$ temperature using a Star cooler. The PBs were sized in the dimension of $18 \times 2100 \times 2800 \mathrm{~mm}$ and sanded using 40, 80, and 100 grit 
sandpapers. Prepared PBs are presented in Fig. 1-B. To determine the effect of the CT on the properties, one of the speed groups was immediately tested and the other one was conditioned for $72 \mathrm{~h}$ in the acclimatization room at the end of all the production processes.

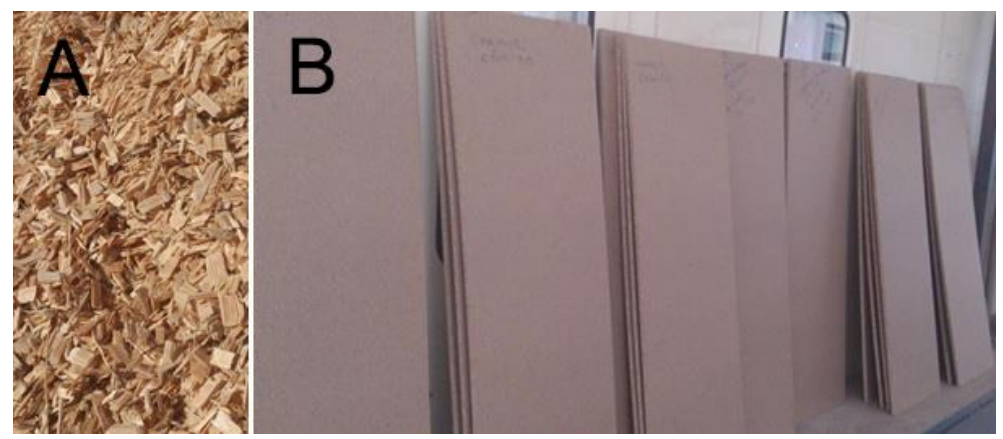

Fig. 1. A) Raw wood material, B) produced PBs

Table 2. Panel Production Parameters

\begin{tabular}{|c|c|}
\hline Press Speed $(\mathrm{mm} / \mathrm{s})$ & 580 and 600 \\
\hline Press Temperature $\left({ }^{\circ} \mathrm{C}\right)$ & $\begin{array}{c}210\left(1^{\text {st }} \text { and } 2^{\text {nd }} \text { sections }\right), 200\left(3^{\text {rd }} \text { section }\right), 185\left(4^{\text {th }} \text { section }\right), \\
\text { and } 180\left(5^{\text {th }} \text { section }\right)\end{array}$ \\
\hline Press Pressure (MPa) & $\begin{array}{c}\left.\left.24\left(1^{\text {st }} \text { section }\right), 16 \text { ( } 2^{\text {nd }} \text { section }\right), 11 \text { ( } 3^{\text {rd }} \text { section }\right), 6\left(4^{\text {th }} \text { section }\right), \\
\left.\text { and } 1.5 \text { ( } 5^{\text {th }} \text { section }\right)\end{array}$ \\
\hline Molar Ratio of UF (molar) & SL:0.98 and CL:1.07 \\
\hline Wood Mixture & $50 \%$ Scot pine $+40 \%$ Sessile oak $+10 \%$ Poplar \\
\hline Adhesive (L/Min) (\%) & 10.80 to 6.00 \\
\hline Hardener (L/Min) (\%) & 1.6 to 2.8 \\
\hline Paraffın (L/Min) (\%) & 0.30 to 25 \\
\hline Adhesive $\mathrm{CL} \mathrm{pH}$ & 8.14 \\
\hline Adhesive SL pH & 8.19 \\
\hline Adhesive Solid Content CL & 65 \\
\hline Adhesive Solid Content SL & 50 \\
\hline Adhesive Molar Ratio UF CL & 1.07 \\
\hline Adhesive Molar Ratio UF SL & 0.98 \\
\hline Mixed Chips Moisture CL (\%) & 5.4 \\
\hline Mixed Chips Moisture SL (\%) & 14 \\
\hline
\end{tabular}

\section{Physical tests}

Thickness, density, MC, TS, and WA of the samples were determined in compliance with the EN 324-1 (1993), EN 323 (1993), EN 322 (1993), EN 317 (1993), and EN 317 (1993) standards, respectively. Physical and mechanical properties and FF of the panels were determined in two different periods (immediately after the production and following the $72 \mathrm{~h}$ of conditioning) to determine the effects of CT.

\section{Mechanical tests}

The modulus of rupture and MOE, IB, and SS of the samples were determined in compliance with the EN 310 (1993), EN 319 (1993), and EN 311 (2002) standards, respectively. The Board Property Tester IB700 (IMAL Srl, San Damaso, Italy) was used to determine both physical and mechanical properties in compliance with the aforementioned standards. 
Free formaldehyde content measurements

The free formaldehyde content of the boards was determined in compliance with the EN 120 (1992) standard. The perforator method was used for the determination of the content as described in the standard.

\section{Statistical analysis}

Analysis of Variance (ANOVA) was performed to reveal the influences of the CPS and $\mathrm{CT}$ on the PB properties. Furthermore, differences between the average values of the groups were presented by Duncan's multiple range tests (DMRT). A scatterplot matrix was created and coefficients of determination between all the variables were presented.

\section{RESULTS AND DISCUSSION}

Mean values for the thickness, density, MC, TS, and WA of the samples, and differences within and between the groups are presented in Table 3. According to the table, the maximum decrease with the increase in CT and increase in CPS were calculated for WA $(-9.8 \%)$ within the $600 \mathrm{~mm} / \mathrm{s}$ groups and TS $(7.75 \%)$ between the $72 \mathrm{~h}$ groups, respectively. When CPS and CT increased, thickness and density values were slightly changed and the percentage changes ranged from -0.3 to $0.4 \%$ and -0.6 to $0.8 \%$, respectively. According to the results, only TS and WA presented remarkable decreases with the increase in CT within the speed groups. The moisture content of the samples was steadily increased (6.69 to 6.89\%) with the increase in CPS and CT. Lower MC values were obtained for the $\mathrm{T}_{1} \mathrm{P}_{580}$ group and the maximum increase in $\mathrm{MC}$ was $2.8 \%$ for the $\mathrm{T}_{72} \mathrm{P}_{600}$ group.

Table 3. Means of the Physical Properties and Differences Within and Between the Groups

\begin{tabular}{|c|c|c|c|c|c|c|}
\hline PB Groups $^{*}$ & $\mathrm{~N}$ & Thickness $(\mathrm{mm})$ & Density $\left(\mathrm{Kg} / \mathrm{m}^{3}\right)$ & $\mathrm{MC}(\%)$ & TS 24 h (\%) & WA 24 h (\%) \\
\hline $\mathrm{T}_{1} \mathrm{P}_{580}$ & 5 & 17.97 & 619 & 6.69 & 17.70 & 73.36 \\
\hline \multirow{2}{*}{$\mathrm{T}_{72} \mathrm{P}_{580}$} & \multirow{2}{*}{5} & 17.984 & 619 & 6.698 & 16.104 & 72.38 \\
& $(0.07)^{\star *}$ & $(0)$ & $(0.06)$ & $(-9.02)$ & $(-1.34)$ \\
\hline \multirow{2}{*}{$\mathrm{T}_{1} \mathrm{P}_{600}$} & \multirow{2}{*}{5} & 17.922 & 624 & 6.72 & 18.478 & 77.428 \\
& $(-0.28)^{\star *}$ & $(0.81)$ & $(0.39)$ & $(4.4)$ & $(5.54)$ \\
\hline \multirow{2}{*}{$\mathrm{T}_{72} \mathrm{P}_{600}$} & \multirow{2}{*}{5} & 17.988 & 620 & 6.888 & 17.352 & 69.87 \\
& & $(0.37)^{\star * *}$ & $(-0.64)$ & $(2.5)$ & $(-6.09)$ & $(-9.76)$ \\
& $(0.02)^{\star * * *}$ & $(0.16)$ & $(2.84)$ & $(7.75)$ & $(-3.47)$ \\
\hline
\end{tabular}

${ }^{*} T_{x}$ is the conditioning time and $P_{y}$ is the press speed, ** \% differences between T1P580, ${ }^{* *} \%$ differences between $\mathrm{T}_{1} \mathrm{P}_{600}$, and ${ }^{* \star * *} \%$ differences between $\mathrm{T}_{72} \mathrm{P}_{580}$

Statistics and Duncan's homogeneity groups (DHG) for the thickness, density, MC, TS, and WA are presented in Table 4. CT and CPS had significant effects on the TS and WA within and between the groups. Mean values of the density and MC presented significant differences only for $\mathrm{T}_{72} \mathrm{P}_{600}$ and $\mathrm{T}_{1} \mathrm{P}_{600}$, respectively. Furthermore, mean values of the thickness were significant within the speed groups while they were not within the CT. 
Table 4. Physical Properties of the Panels and Statistics

\begin{tabular}{|c|c|c|c|c|c|c|c|c|c|c|}
\hline \multirow{2}{*}{$\begin{array}{l}\text { Physical } \\
\text { Properties }\end{array}$} & \multirow{2}{*}{ Groups } & \multirow{2}{*}{$\mathrm{N}$} & \multirow{2}{*}{ Mean } & \multirow{2}{*}{$\mathrm{DHG}^{*}$} & \multirow{2}{*}{$\begin{array}{l}\text { Std. } \\
\text { Dev. }\end{array}$} & \multirow{2}{*}{$\begin{array}{l}\text { Std. } \\
\text { Error }\end{array}$} & \multicolumn{2}{|c|}{$95 \% \mathrm{Cl}$ for Mean } & \multirow{2}{*}{ Min. } & \multirow{2}{*}{ Max. } \\
\hline & & & & & & & Lower & Upper & & \\
\hline \multirow{4}{*}{$\begin{array}{l}\text { Thickness } \\
\quad(\mathrm{mm})\end{array}$} & $\mathrm{T}_{1} \mathrm{P}_{580}$ & 5 & 17.922 & A & .02683 & .01200 & 17.8887 & 17.9553 & 17.90 & 17.96 \\
\hline & $\mathrm{T}_{72} \mathrm{P}_{580}$ & 5 & 17.984 & $\mathrm{~B}$ & .02074 & .00927 & 17.9583 & 18.0097 & 17.96 & 18.01 \\
\hline & $\mathrm{T}_{1} \mathrm{P}_{600}$ & 5 & 17.922 & $A$ & .02683 & .01200 & 17.8887 & 17.9553 & 17.90 & 17.96 \\
\hline & $\mathrm{T}_{72} \mathrm{P}_{600}$ & 5 & 17.988 & $B$ & .01483 & .00663 & 17.9696 & 18.0064 & 17.97 & 18.01 \\
\hline \multirow{4}{*}{$\begin{array}{l}\text { Density } \\
\left(\mathrm{g} / \mathrm{cm}^{3}\right)\end{array}$} & $\mathrm{T}_{1} \mathrm{P}_{580}$ & 5 & 619 & $A$ & 1.87 & 0.84 & 616.68 & 621.32 & 617.0 & 621.0 \\
\hline & $\mathrm{T}_{72} \mathrm{P}_{580}$ & 5 & 619 & A & 1.58 & 0.71 & 617.04 & 620.96 & 617.0 & 621.0 \\
\hline & $T_{1} P_{600}$ & 5 & 624 & $B$ & 2.35 & 1.05 & 621.09 & 626.91 & 621.0 & 626.0 \\
\hline & $\mathrm{T}_{72} \mathrm{P}_{600}$ & 5 & 620 & $A$ & 2.35 & 1.05 & 617.09 & 622.91 & 617.0 & 622.0 \\
\hline \multirow{4}{*}{$\begin{array}{l}\text { M.C. } \\
(\%)\end{array}$} & $T_{1} P_{580}$ & 5 & 6.694 & $A$ & 0.03 & 0.01 & 6.65 & 6.73 & 6.65 & 6.74 \\
\hline & $\mathrm{T}_{72} \mathrm{P}_{580}$ & 5 & 6.698 & $A$ & 0.15 & 0.07 & 6.51 & 6.89 & 6.50 & 6.85 \\
\hline & $T_{1} P_{600}$ & 5 & 6.72 & $\mathrm{~A}$ & 0.06 & 0.03 & 6.65 & 6.79 & 6.64 & 6.77 \\
\hline & $\mathrm{T}_{72} \mathrm{P}_{600}$ & 5 & 6.888 & $B$ & 0.04 & 0.02 & 6.83 & 6.94 & 6.84 & 6.94 \\
\hline \multirow{4}{*}{$\begin{array}{c}\text { TS } 24 \mathrm{~h} \\
(\%)\end{array}$} & $\mathrm{T}_{1} \mathrm{P}_{580}$ & 5 & 17.7 & $C$ & .02739 & .01225 & 17.6660 & 17.7340 & 17.67 & 17.74 \\
\hline & $\mathrm{T}_{72} \mathrm{P}_{580}$ & 5 & 16.104 & $A$ & .07503 & .03356 & 16.0108 & 16.1972 & 16.02 & 16.21 \\
\hline & $T_{1} P_{600}$ & 5 & 18.478 & $D$ & .03194 & .01428 & 18.4383 & 18.5177 & 18.44 & 18.52 \\
\hline & $\mathrm{T}_{72} \mathrm{P}_{600}$ & 5 & 17.352 & $B$ & .05119 & .02289 & 17.2884 & 17.4156 & 17.29 & 17.41 \\
\hline \multirow{4}{*}{$\begin{array}{l}\text { WA } 24 \mathrm{~h} \\
(\%)\end{array}$} & $T_{1} P_{580}$ & 5 & 73.362 & $C$ & 0.03 & 0.01 & 73.32 & 73.40 & 73.32 & 73.40 \\
\hline & $\mathrm{T}_{72} \mathrm{P}_{580}$ & 5 & 72.38 & $B$ & 0.07 & 0.03 & 72.30 & 72.46 & 72.30 & 72.45 \\
\hline & $T_{1} P_{600}$ & 5 & 77.428 & $D$ & 0.04 & 0.02 & 77.38 & 77.47 & 77.38 & 77.47 \\
\hline & $\mathrm{T}_{72} \mathrm{P}_{600}$ & 5 & 69.87 & $A$ & 0.06 & 0.03 & 69.79 & 69.95 & 69.81 & 69.94 \\
\hline
\end{tabular}

* DHG, Duncan homogeneity groups

Mean values for MOR, MOE, IB, SS, and FF, and differences within and between the groups are presented in Table 5. As can be seen in the table, there were remarkable differences within and between the groups. The maximum increase and decrease in the mechanical properties were observed for MOR (4.4\%) and SS (-10.6\%) in the $\mathrm{T}_{1} \mathrm{P}_{600}$, respectively. The modulus of rupture steadily increased (11.19 to $11.69 \mathrm{MPa})$ with the increase in CPS and CT. On the contrary to $600 \mathrm{~mm} / \mathrm{s}$ CPS, MOE decreased with the increase in CT in $580 \mathrm{~mm} / \mathrm{s}$. Furthermore, around a 1.3\% increase in MOE was observed when CT increased within the $600 \mathrm{~mm} / \mathrm{s}$ CPS groups. Internal bond values were increased (3.1\%) with the increase in CT; however, increasing speed between the immediate CT groups caused around 2.4\% decrease. The same behavior with the MOE was observed for SS. Surface soundness values were decreased with the increase in CT and CPS except for $\mathrm{T}_{72} \mathrm{P}_{600}$. The maximum decrease $(10.6 \%)$ in $\mathrm{SS}$ values was observed between $\mathrm{T}_{1} \mathrm{P}_{580}$ and $\mathrm{T}_{1} \mathrm{P}_{600}$. As can be seen in Table 5, the FF was the most prominent parameter influenced by the increase in CPS for unconditioned PB, and a $21.1 \%$ decrease in FF was observed. However, this percentage was decreased to $-8.8 \%$ when the samples were conditioned for $72 \mathrm{~h}$. The $72 \mathrm{~h}$ conditioning caused a $12.8 \%$ reduction in FF in $580 \mathrm{~mm} / \mathrm{s}$ speed groups while it was only $0.8 \%$ in $600 \mathrm{~mm} / \mathrm{s}$. 
Table 5. Mechanical Properties and FF of the Groups

\begin{tabular}{|c|c|c|c|c|c|c|}
\hline PB Group & $\mathrm{N}$ & MOR (MPa) & MOE (MPa) & IB (MPa) & SS (MPa) & Formaldehyde $(\mathrm{mg} / 100 \mathrm{~g})$ \\
\hline $\mathrm{T}_{1} \mathrm{P}_{580}$ & 5 & 11.192 & 2372 & 0.332 & 1.428 & 5.146 \\
\hline \multirow{2}{*}{$\mathrm{T}_{72} \mathrm{P}_{580}$} & \multirow{2}{*}{5} & 11.206 & 2263 & 0.338 & 1.292 & 4.486 \\
& & $(0.13)^{\star}$ & $(-4.6 \%)$ & $(1.81)$ & $(-9.52)$ & $(-12.83)$ \\
\hline \multirow{2}{*}{$\mathrm{T}_{1} \mathrm{P}_{600}$} & \multirow{2}{*}{5} & 11.682 & 2256 & 0.324 & 1.276 & 4.058 \\
& & $(4.38)^{\star}$ & $(-4.89)$ & $(-2.41)$ & $(-10.64)$ & $(-21.14)$ \\
\hline \multirow{3}{*}{$\mathrm{T}_{72} \mathrm{P}_{600}$} & \multirow{2}{*}{5} & 11.686 & 2285 & 0.334 & 1.310 & 4.090 \\
& & $(0.03)^{\star *}$ & $(1.29)$ & $(3.09)$ & $(2.66)$ & $(0.79)$ \\
& & $(4.28)^{\star * *}$ & $(0.97)$ & $(-1.18)$ & $(1.39)$ & $(-8.83)$ \\
\hline
\end{tabular}

* $\%$ diff. between T1P580, ${ }^{* *} \%$ diff. between T1P600, and ${ }^{* * *} \%$ diff. between T72P580

Table 6. Mechanical Properties of the Panels and Statistics

\begin{tabular}{|c|c|c|c|c|c|c|c|c|c|c|}
\hline \multirow{2}{*}{$\begin{array}{l}\text { Mechanical } \\
\text { Properties }\end{array}$} & \multirow{2}{*}{ Groups } & \multirow{2}{*}{$\mathrm{N}$} & \multirow{2}{*}{ Mean } & \multirow{2}{*}{$\mathrm{DHG}^{*}$} & \multirow{2}{*}{$\begin{array}{l}\text { Std. } \\
\text { Dev. }\end{array}$} & \multirow{2}{*}{$\begin{array}{l}\text { Std. } \\
\text { Error }\end{array}$} & \multicolumn{2}{|c|}{$95 \% \mathrm{Cl}$ for Mean } & \multirow{2}{*}{ Min. } & \multirow{2}{*}{ Max. } \\
\hline & & & & & & & Lower & Upper & & \\
\hline \multirow{4}{*}{$\begin{array}{l}\text { MOR } \\
(\mathrm{MPa})\end{array}$} & $T_{1} P_{580}$ & 5 & 11.192 & A & 0.03 & 0.01 & 11.16 & 11.22 & 11.16 & 11.22 \\
\hline & $\mathrm{T}_{72} \mathrm{P}_{580}$ & 5 & 11.206 & $A$ & 0.01 & 0.01 & 11.19 & 11.22 & 11.19 & 11.22 \\
\hline & $T_{1} P_{600}$ & 5 & 11.682 & B & 0.04 & 0.02 & 11.63 & 11.73 & 11.64 & 11.74 \\
\hline & $T_{72} P_{600}$ & 5 & 11.686 & $B$ & 0.05 & 0.02 & 11.63 & 11.74 & 11.63 & 11.74 \\
\hline \multirow{4}{*}{$\begin{array}{l}\text { MOE } \\
(\mathrm{MPa})\end{array}$} & $T_{1} P_{580}$ & 5 & 2372 & D & 5.15 & 2.30 & 2365.61 & 2378.39 & 2367 & 2378 \\
\hline & $\mathrm{T}_{72} \mathrm{P}_{580}$ & 5 & 2263 & B & 3.87 & 1.73 & 2258.19 & 2267.81 & 2258 & 2267 \\
\hline & $T_{1} P_{600}$ & 5 & 2256 & $A$ & 0.00 & 0.00 & 2256.00 & 2256.00 & 2256 & 2256 \\
\hline & $T_{72} P_{600}$ & 5 & 2285 & $\mathrm{C}$ & 3.61 & 1.61 & 2280.52 & 2289.48 & 2280 & 2289 \\
\hline \multirow{4}{*}{$\begin{array}{c}\mathrm{IB} \\
(\mathrm{MPa})\end{array}$} & $T_{1} P_{580}$ & 5 & 0.332 & $A$ & 0.03 & 0.01 & 0.30 & 0.36 & 0.30 & 0.36 \\
\hline & $T_{72} P_{580}$ & 5 & 0.338 & $A$ & 0.02 & 0.01 & 0.32 & 0.36 & 0.32 & 0.36 \\
\hline & $T_{1} P_{600}$ & 5 & 0.324 & $A$ & 0.02 & 0.01 & 0.31 & 0.34 & 0.30 & 0.34 \\
\hline & $\mathrm{T}_{72} \mathrm{P}_{600}$ & 5 & 0.334 & A & 0.02 & 0.01 & 0.31 & 0.36 & 0.31 & 0.37 \\
\hline \multirow{4}{*}{$\begin{array}{c}\mathrm{SS} \\
(\mathrm{MPa})\end{array}$} & $T_{1} P_{580}$ & 5 & 1.428 & $\mathrm{~B}$ & 0.04 & 0.02 & 1.38 & 1.47 & 1.38 & 1.46 \\
\hline & $T_{72} P_{580}$ & 5 & 1.292 & $A$ & 0.03 & 0.01 & 1.25 & 1.33 & 1.25 & 1.33 \\
\hline & $T_{1} P_{600}$ & 5 & 1.276 & A & 0.03 & 0.01 & 1.24 & 1.32 & 1.22 & 1.30 \\
\hline & $\mathrm{T}_{72} \mathrm{P}_{600}$ & 5 & 1.31 & A & 0.03 & 0.01 & 1.27 & 1.35 & 1.28 & 1.35 \\
\hline
\end{tabular}

* DHG, Duncan homogeneity groups

Statistics and DHG for the MOR, MOE, IB, and SS are presented in Table 6. CPS had statistically significant influences on the MOR. The influence of CT on the MOR was insignificant. All the MOE values differed significantly from each other in terms of CPS and CT. Contrary to MOE, neither CPS nor CT had statistically significant influences on the IB values of the boards. Only $\mathrm{T}_{1} \mathrm{P}_{580}$ values of the SS presented statistically significant differences. Statistics and DHG for the FF of the samples are presented in Table 7.

Table 7. Free Formaldehyde Content of the Panels and Statistics

\begin{tabular}{|c|c|c|c|c|c|c|c|c|c|c|}
\hline \multirow{6}{*}{$\begin{array}{c}\text { Free } \\
\text { Formaldehyde } \\
\text { Content } \\
(\mathrm{mg} / 100 \mathrm{~g})\end{array}$} & \multirow{2}{*}{ Groups } & \multirow{2}{*}{$\mathrm{N}$} & \multirow{2}{*}{ Mean } & \multirow{2}{*}{$\mathrm{DHG}^{*}$} & \multirow{2}{*}{$\begin{array}{l}\text { Std. } \\
\text { Dev. }\end{array}$} & \multirow{2}{*}{$\begin{array}{l}\text { Std. } \\
\text { Error }\end{array}$} & \multicolumn{2}{|c|}{$95 \% \mathrm{Cl}$ for Mean } & \multirow{2}{*}{ Min. } & \multirow{2}{*}{ Max. } \\
\hline & & & & & & & Lower & Upper & & \\
\hline & & 5 & & $\mathrm{C}$ & 0.05 & 0.02 & 5.08 & & 5.10 & 5.21 \\
\hline & & 5 & & $B$ & 0.25 & 0.11 & 4.1 & & 4 & 4.70 \\
\hline & & 5 & 4.05 & $A$ & 0.04 & 0.02 & 4.0 & & 4.02 & 4.10 \\
\hline & $T_{72} P_{600}$ & 5 & 4.09 & A & 0.06 & 0.03 & 4.02 & 4.16 & 4.02 & 4.16 \\
\hline
\end{tabular}

* Duncan homogeneity groups

According to DMRT, CPS and CT had statistically significant influences on the FF of the boards. However, no statistically significant difference was observed for the CT 
within the $600 \mathrm{~mm} / \mathrm{s}$ groups. According to Nemli and Öztürk (2006) an increase in specific gravity, shelling ratio, and pressure caused an increase in FF of the PB. In the current study, a slight increase $(0.8 \%)$ in density was observed when CPS was increased from 580 to 600 $\mathrm{mm} / \mathrm{s}$. Plus and minus error bars representing uncertainty or variation of the physical and mechanical properties and FF in terms of panel groups are presented in Figs. 3 through 5.
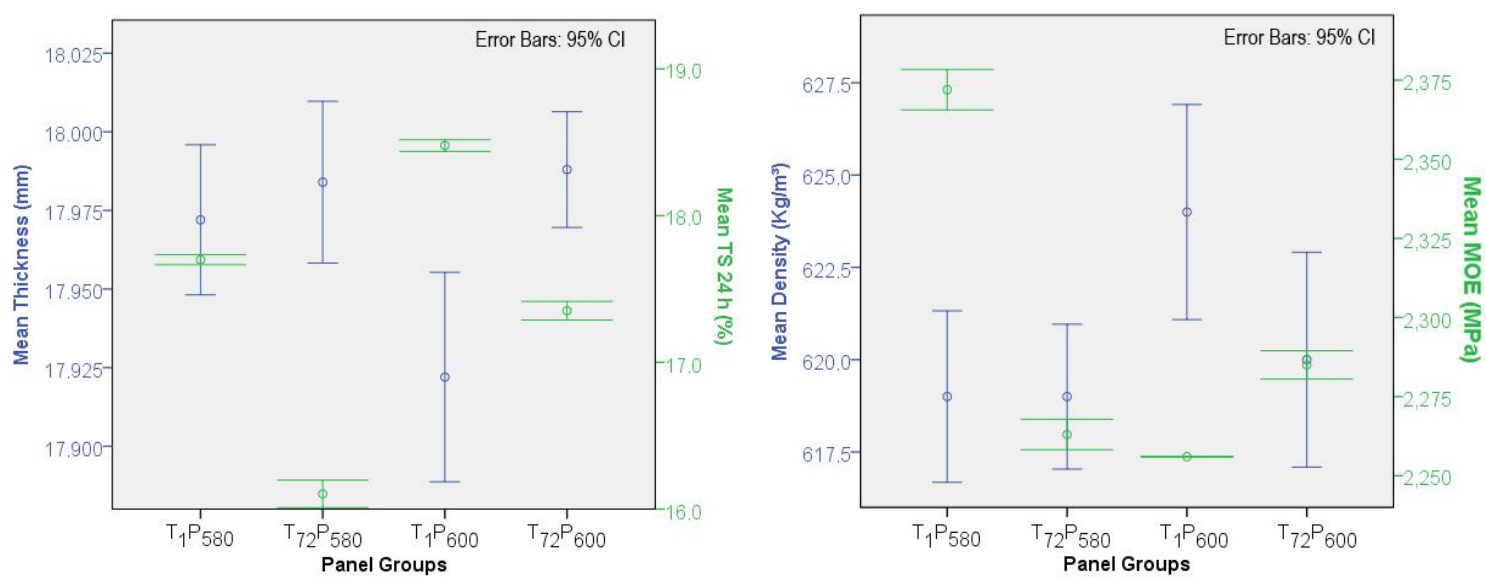

Fig. 3. Thickness, thickness swelling, density, and MOE properties of the panels
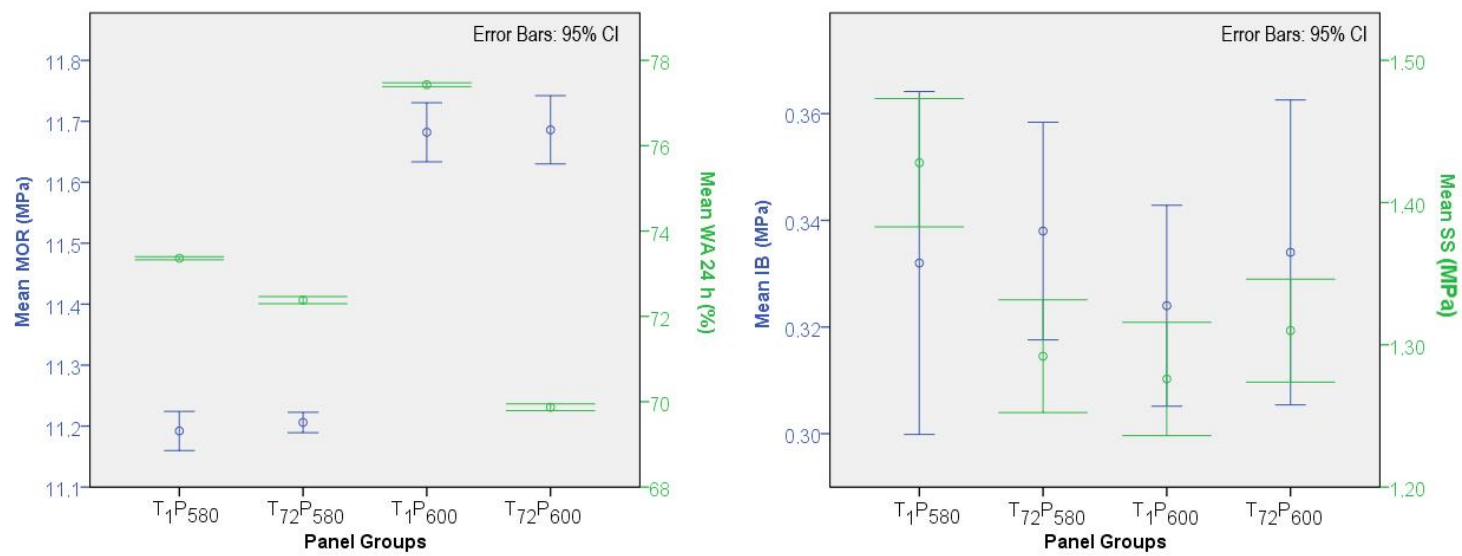

Fig. 4. MOR, WA, IB, and SS properties of the panels

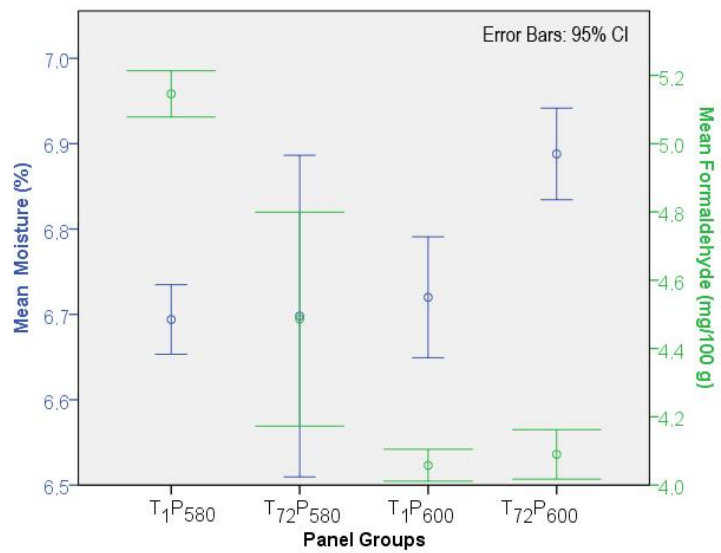

Fig. 5. Moisture and FF of the panels 
Strength properties strongly depend on the density gradients of the panels. This means that decreasing the press time by setting the manufacturing parameters may cause proportional decreases in the strength of the boards (Heebink et al. 1972). In the current study, CPS was increased around 3.5\%, and therefore a decrease in press time was obvious. However, the MOR of the PBs was increased (around 4.3\%) with the increase in CPS. Also, slight increases (0.97\% and $1.39 \%$ ) in MOE and SS of the PBs were calculated when CPS increased. These increases were obtained after $72 \mathrm{~h}$ of conditioning. On the contrary, the increase in CPS caused reductions in MOE, IB, and SS of the PB that were tested immediately.

The temperature in the pressing also has influences on the quality of produced PB. The characteristics of $\mathrm{PB}$ are advanced due to the increased adhesive bonding rate because of the increased pressing temperature (Malanit et al. 2009; Ramezanpoor Maraghi et al. 2018). Increasing the CPS without changing the press temperature may decrease the heat transfer period. Therefore, the effective temperature on the continuous pressing may alter the results of this study. To identify this issue, the temperature should be taken into consideration in future studies as a crucial factor that has influences on the process.

According to EN 312 (2010), minimum MOR and IB values of PB (13 mm < thickness $\leq 20 \mathrm{~mm}$ ) for general-purpose dry use (Type P1) are 11.5 and $0.25 \mathrm{MPa}$, respectively. Furthermore, minimum MOR, MOE, IB, and SS values of Type P2 PB (interior use including furniture, dry conditions) are 13, 1600, 0.35, and $0.8 \mathrm{MPa}$, respectively. The minimum value for the TS $24 \mathrm{~h}$ of PB is 14\% (Type P3, interior use, wet conditions). Modulus of rupture for general and furniture manufacturing, and MOE for general purposes of the PBs are also reported as 11.5 and $13 \mathrm{MPa}$, and $1600 \mathrm{MPa}$, respectively (Nemli and Çolakoğlu 2005).

In this study, the MOE values of all the groups were considerably higher than the minimum requirements for both interior and general purposes. On the other side, only $\mathrm{T}_{1} \mathrm{P}_{580}$ fulfilled the requirement of the dry condition for the structural purpose. Furthermore, none of the groups fulfilled the minimum requirements for heavy-duty structural utilization.

As can be seen in Table 5, the MOR of PBs that were produced using $580 \mathrm{~mm} / \mathrm{s}$ CPS was slightly lower $(2.68 \%)$ than the general-purpose reference values. On the contrary to $580 \mathrm{~mm} / \mathrm{s}$ speed groups, MOR of the $600 \mathrm{~mm} / \mathrm{s}$ groups was slightly higher $(1.6 \%)$ than the general-purpose reference values reported by EN 312 (2010) and Nemli and Çolakoğlu (2005). According to standard, these PBs were neither suitable for interior nor structural because of the low MOR values, and only PBs that were produced using $600 \mathrm{~mm} / \mathrm{s}$ CPS can be utilized just for general purposes.

The IB values of all the groups were considerably higher $\left(40.8 \%\right.$ for $\left.\mathrm{T}_{72} \mathrm{P}_{580}\right)$ than the minimum values for general purpose (P1), and slightly lower $(3.4 \%)$ than the minimum values for interior purposes (P2 and P4). However, IB values of this study were significantly lower (24.9 to $51.7 \%$ ) than the minimum values of P3, P5-7 type PBs.

The lower and higher TS $24 \mathrm{~h}$ values $\left(\mathrm{T}_{72} \mathrm{P}_{580}\right.$ and $\left.\mathrm{T}_{1} \mathrm{P}_{600}\right)$ of this study were 15 to $32 \%$ and 7.4 to $23.2 \%$ higher than the reference values of P3 and P4 or P6 types PBs, respectively. However, TS 24 h values of P5 and P7 type PBs were significantly lower than the results of this study, and the differences between lower and higher values of this study. The P5 and P7 values ranged from 61 to $84.8 \%$ and 101 to $131 \%$, respectively. Therefore, it's seen that produced PBs were able to meet neither interior nor structural requirements in terms of TS $24 \mathrm{~h}$. 
According to EN 312 (2010), SS of the P2 type PB (13 mm $<$ thickness $\leq 20 \mathrm{~mm})$ is $0.8 \mathrm{MPa}$. The SS values of this study ranged from $1.267\left(\mathrm{~T}_{1} \mathrm{P}_{600}\right)$ to $1.428\left(\mathrm{~T}_{1} \mathrm{P}_{580}\right)$, and these values were 58.4 and $78.5 \%$ higher than the minimum value of the reference. Therefore, all the produced PBs conform to the standard in terms of SS.

As mentioned in the introduction, studies have evaluated the effects of different types of variables on the physical and mechanical properties and FE of the PBs. However, the effect of CPS in PB production was evaluated in limited studies, while CT had not yet been studied. Ciobanu et al. (2014) stated that low speed and corresponding high press values cause increases in mechanical properties. Internal bond, TS, and WA slightly varied between the groups. In this study, only MOE $\left(\mathrm{T}_{1} \mathrm{P}_{580}\right)$ and $\mathrm{IB}\left(\mathrm{T}_{72} \mathrm{P}_{580}\right)$ values were the maxima at low CPS as mentioned for OSB. On the contrary to OSB, MOR was considerably increased with the increase in CPS in this study.

Candan et al. (2012) stated that TS (2 and $24 \mathrm{~h}$ ) values were decreased with the increase in CPS. However, an opposing behavior was observed for TS $24 \mathrm{~h}$ in this study. Çamlibel (2020b) stated that further increases other than optimum set-up values in press time and temperature cause adverse effects on the PB properties. Press closing time has an adverse relation with density and an increase in PCT causes density reduction and precured layer, which are responsible for the decreases in bending properties (Miyamoto et al. 2002). Porosity, water diffusion, and absorption are related to the density, and low density in the core layer cause increases in these properties. Furthermore, high density in the surface layers positively influences the bending properties. Moreover, IB has an adverse relationship with core layer density. Also, SR of the PB produced using a continuous press was higher than a one-opening press due to surface density differences (Nemli and Demirel 2006). Time and temperature combinations should be optimized to obtain a proper cure of binder and loss of enough moisture to avoid steam blisters, but it should be taken into consideration that reducing the time in pressing can cause a proportional reduction in strength of board (Heebink et al. 1972). An increase in pressing time provides advances in mechanical properties but for better TS and WA performance press time can be shorter (Ferrandez-Villena et al. 2020).

Addition of wollastonite nanofibers (10\% dry wt.) in the UF resin used in MDF production using the mixture of beech, alder, maple, hornbeam, and poplar species provided around $11.5 \%$ improvement in thermal conductivity (Taghiyari et al. 2013), which is one of the essential factors for heat distribution. Furthermore, pressing time can be significantly reduced when the accelerated homogenous heat distribution is achieved by applying such modification agents, and proper resin curing and target MC levels can be achieved. Therefore, such minerals can be used for increasing the CPS.

As can be seen in the results of this study, CPS and CT have different influences on the PB properties instead of overall improvement or reduction. Therefore, CPS corresponding to press time should be in accordance with temperature and pressure to provide achievements. Due to the lack of comparative data in the literature, the discussion section of this study is limited. Furthermore, it is expected that this study may provide such data for future studies.

\section{CONCLUSIONS}

1. The influence of the continuous press speed (CPS) and conditioning time (CT) on the physical and mechanical properties and free formaldehyde (FF) of the particleboard 
(PB) were evaluated in this study. When the temperature and pressure are constant in pressing, press speed defines the pressing time. Therefore, when the CPS increases, press time decreases. As a result of the duration decrease, the polymerization of resin would be affected. This circumstance influences the physical and mechanical properties of PB but in a different manner, as seen in the results.

2. Only moisture content (MC) and modulus of rupture (MOR) were increased with the increase in both CPS and CT. These increases within the CPS groups were not statistically significant for MOR. However, a significant difference within or between the MC groups was observed only for $72 \mathrm{~h} \mathrm{CT}$ and $600 \mathrm{~mm} / \mathrm{s}$ CPS. It's expected that statistically significant differences would be observed between the CPS groups instead of CT groups. This is reasonable because when the $\mathrm{CP}$ parameters are constant such as temperature and pressure, pressing time is shortened with the increasing of speed, and evaporation of moisture inside the mat decreases. In these circumstances, it's thought that PBs interacted with surrounding conditions while in storage.

3. Continuous press speed has no influence on thickness, while CT provided some slight but statistically significant increases. A saw tooth behavior was observed. As mentioned above, interaction with the surrounding at conditioning is assumed as one of the reasons for the differences.

4. Modulus of elasticity and surface soundness (SS) were decreased with the increase in CPS. However, CT had an adverse effect on MOE and SS in CPS groups. These values were decreased and increased with the increase in CT when the CPS was $580 \mathrm{~mm} / \mathrm{s}$ and $600 \mathrm{~mm} / \mathrm{s}$, respectively. Furthermore, means of MOE within and between groups presented statistical differences. On the contrary, only SS values of $\mathrm{T}_{1} \mathrm{P}_{580}$ presented statistically significant differences.

5. As in the MOE and SS, FF presented the same behavior relative to CPS and CT. An adverse effect of CT was observed when CPS increased. Formaldehyde emission was decreased when CPS increased. However, FF deceased and increased with the increase in CT when CPS was $580 \mathrm{~mm} / \mathrm{s}$ and $600 \mathrm{~mm} / \mathrm{s}$, respectively. Furthermore, no statistically significant differences were observed for CT at $600 \mathrm{~mm} / \mathrm{s} \mathrm{CPS}$.

6. Continuous press speed and CT had adverse effects on WA and TS. Water absorption and TS were increased and decreased with the increase in CPS and CT, respectively. Statistical significant differences were observed within and between the groups. This phenomenon was related to the issue mentioned in the first conclusion.

7. Conditioning time had no influence on density when CPS was $580 \mathrm{~mm} / \mathrm{s}$. On the contrary, CT adversely influenced the density when CPS was $600 \mathrm{~mm} / \mathrm{s}$, and density was increased with the increase in CPS.

8. Both CPS and CT had no statistically significant influences on internal bond (IB), but they oppositely affected IB. Internal bonding was increased and decreased with the increase in CT and CPS, respectively. Press time is one of the essential pressing parameters for the exact cure of the resin. Pressing time decreases as a natural consequence of the increase in press speed. Decreases in time, while other parameters are constant, may cause improper polymerization and reduction in bonding. Therefore, time, temperature, pressure, and speed should be optimized to obtain better physical and mechanical properties. 


\section{ACKNOWLEDGMENTS}

The authors would like to thank Enus Koç and the director of the Kastamonu Integrated Wood Inc. factories as well as Uğur Çelik, the glue production manager.

\section{REFERENCES CITED}

Barragàn-Lucas, A. D., Llerena-Miranda, C., Quijano-Avilés, M. F., Chóez-Guaranda, I. A., Maldonado-Guerrero, L. C., and Manzano-Santana, P. I. (2019). "Effect of resin content and pressing temperature on banana pseudo-stem particle boards properties using full factorial design," Anais da Academia Brasileira de Ciencias 91(4), article ID e20180302. DOI: 10.1590/0001-3765201920180302

Buyuksari, U., Ayrilmis, N., Avci, E., and Koc, E. (2010). "Evaluation of the physical, mechanical properties and formaldehyde emission of particleboard manufactured from waste stone pine (Pinus pinea L.) cones," Bioresource Technology 101(1), 255-259. DOI: 10.1016/j.biortech.2009.08.038

Çamlıbel, O. (2020a). "Physical properties and formaldehyde emission effect of hot press parameters," Artvin Coruh University Journal of Forestry Faculty 21(2), 276-283.

DOI: 10.17474/artvinofd.740136

Çamlibel, O. (2020b). "Production of medium density fiberboard (MDF) from birch (Betula pendula L.) wood biomass," Turkish Journal of Forestry| Türkiye Ormancilık Dergisi, 174-178. DOI: 10.18182/tjf.731926

Çamlıbel, O., and Yılmaz Aydın, T. (2020). "Effects of zeolite on some physical properties and formaldehyde release of medium density fiberboard," ProLigno, 16(4), 22-28.

Candan, Z., Akbulut, T., Wang, S., Zhang, X., and Faruk Sisci, A. (2012). "Layer thickness swell characteristics of medium density fibreboard (MDF) panels affected by some production parameters," Wood Research 57(3), 441-452.

Ciobanu, V. D., Zeleniuc, O., Dumitrascu, A., Lepadatescu, B., and Iancu, B. (2014). "The influence of speed and press factor on oriented strand board performance in continuous press," BioResources 9(4), 6805-6816. DOI: 10.15376/biores.9.4.68056816

Çolak, S., Öztürk, H., and Demir, A. (2015). "Effects of tannin and chitosan on formaldehyde emission of particleboard panels," Selçuk-Teknik 14(2), 613-622.

EN 120 (1992). "Wood based panels- Determination of formaldehyde content- Extraction method called the perforator method," European Committee for Standardization, Brussels, Belgium.

EN 310 (1993). "Wood- Based panels. Determination of modulus of elasticity in bending and of bending strength," European Committee for Standardization, Brussels, Belgium.

EN 311 (2002). "Wood-based panels. Surface soundness of particle boards, test method," European Committee for Standardization, Brussels, Belgium.

EN 312 (2010). "Particleboards - Specifications," European Committee for Standardization, Brussels, Belgium.

EN 317 (1993). "Particleboards and fibreboards. Determination of swelling in thickness after immersion in water," European Committee for Standardization, Brussels, Belgium. 
EN 319 (1993). "Particleboards and fibreboards. Determination of tensile strength perpendicular to the plane of the board," European Committee for Standardization, Brussels, Belgium.

EN 322 (1993). "Wood-based panels. Determination of moisture content," European Committee for Standardization, Brussels, Belgium.

EN 323 (1993). "Wood- Based panels. Determination of density," European Committee for Standardization, Brussels, Belgium.

EN 324-1 (1993). "Wood- Based panels- Determination of dimensions of boards- Part 1: Determination of thickness, width and length," European Committee for Standardization, Brussels, Belgium.

Ferrandez-Villena, M., Ferrandez-Garcia, C. E., Garcia-Ortuño, T., Ferrandez-Garcia, A., and Ferrandez-Garcia, M. T. (2020). "The influence of processing and particle size on binderless particleboards made from Arundo donax L. Rhizome," Polymers 12(3), article no. 696. DOI: 10.3390/polym12030696

Godbille, F. D. (2002). "A simualtion model for the hot pressing ofparticleboard," The University of New Brunswick.

Güler, C., and Sancar, S. (2016). "The principle of a particle board plant and the effect of pressing techniques on board quality," Düzce University Faculty of Forestry Journal of Forestry 12(1), 1-10.

Heebink, B., Lehmann, W. F., and Hefty, F. V. (1972). Reducing Particleboard Pressing Time: Exploratory Study (Report No. FPL-180), U.S. Department of Agriculture Forest Products Laboratory, Madison, WI, USA.

İstek, A., Özlüsoylu, İ., Onat, S. M., and Özlüsoylu, Ş. (2018). "Formaldehyde emission problems and solution recommendations on wood-based boards: A review," Journal of Bartin Faculty of Forestry 20(2), 382-387. DOI: 10.24011/barofd.425409

Iswanto, A. H., Febrianto, F., Hadi, Y. S., Ruhendi, S., and Hermawan, D. (2014). "The effect of pressing temperature and time on the quality of particle board made from jatropha fruit hulls treated in acidic condition," MAKARA Journal of Technology Series 17(3), 145-151. DOI: 10.7454/mst.v17i3.2930

Jasmani, L., Rusli, R., Khadiran, T., Jalil, R., and Adnan, S. (2020). “Application of nanotechnology in wood-based products industry: A review," Nanoscale Research Letters 15(1). DOI: 10.1186/s11671-020-03438-2

Kelly, M. W. (1977). Critical Literature Review of Relationships Between Processing Parameters and Physical Properties of Critical Literature Review of Relationships Between Processing Parameters and Physical Properties (Report No. FPL-10), U.S. Department of Agriculture Forest Products Laboratory, Madison, WI, USA.

Lehmann, W. F., Geimer, R. L., and Hefty, F. V. (1973). "Factors affecting particleboard pressing time: Interaction with catalyst systems," U S Forest Prod. Lab., Res. Pap. FPL 208.

Leng, W., Hunt, J. F., and Tajvidi, M. (2017). "Effects of density, cellulose nanofibrils addition ratio, pressing method, and particle size on the bending properties of wetformed particleboard," BioResources 12(3), 4986-5000. DOI: 10.15376/biores. 12.3.4986-5000

Li, X., Cai, Z., Winandy, J. E., and Basta, A. H. (2010). "Selected properties of particleboard panels manufactured from rice straws of different geometries," Bioresource Technology 101(12), 4662-4666. DOI: 10.1016/j.biortech.2010.01.053

Lum, W. C., Lee, S. H., and H'ng, P. S. (2014). "Effects of formaldehyde catcher on some properties of particleboard with different ratio of surface to core layer," Asian 
Journal of Applied Sciences 7(1), 22-29. DOI: 10.3923/ajaps.2014.22.29

Lv, Y., Liu, Y., Jing, W., Woźniak, M., Damaševičius, R., Scherer, R., and Wei, W. (2020). "Quality control of the continuous hot pressing process of medium density fiberboard using fuzzy failure mode and effects analysis," Applied Sciences (Switzerland), 10(13). DOI: 10.3390/app10134627

Malanit, P., Barbu, M. C., and Frühwald, A. (2009). "The gluability and bonding quality of an Asian bamboo (Dendrocalamus asper) for the production of composite lumber," Journal of Tropical Forest Science 21(4), 361-368.

Mantanis, G. I., Athanassiadou, E. T., Barbu, M. C., and Wijnendaele, K. (2018). "Adhesive systems used in the European particleboard, MDF and OSB industries," Wood Material Science and Engineering. DOI: 10.1080/17480272.2017.1396622

Mirski, R., Derkowski, A., Dziurka, D., Dukarska, D., and Czarnecki, R. (2019). "Effects of a chipboard structure on its physical and mechanical properties," Materials 12(22), article no. 3777. DOI: 10.3390/ma12223777

Miyamoto, K., Suzuki, S., Inagaki, T., and Iwata, R. (2002). "Effects of press closing time on mat consolidation behavior during hot pressing and on linear expansion of particleboard," Journal of Wood Science 48(4), 309-314. DOI: 10.1007/BF00831352

Nemli, G. (2002). "Factors affecting the production of E1 type particleboard," Turkish Journal of Agriculture and Forestry 26(1), 31-36.

Nemli, G., and Çolakoğlu, G. (2005). "Effects of mimosa bark usage on some properties of particleboard," Turkish Journal of Agriculture and Forestry 29(3), 227-230.

Nemli, G., and Demirel, S. (2006). "Relationship between the density profile and the technological properties of the particleboard composite," Journal of Composite Materials. DOI: 10.1177/0021998306069892

Nemli, G., Kalaycioğlu, H., and Akbulut, T. (2004). "Influence of press type on the technological properties of particleboard," Artvin Çoruh Üniversitesi Orman Fakültesi Dergisi, (1-2), 89-95. DOI: 10.17474/acuofd.80258

Nemli, G., and Öztürk, I. (2006). "Influences of some factors on the formaldehyde content of particleboard," Building and Environment 41(6), 770-774. DOI:

10.1016/j.buildenv.2005.03.016

Nitu, I. P., Islam, M. N., Ashaduzzaman, M., Amin, M. K., and Shams, M. I. (2020). "Optimization of processing parameters for the manufacturing of jute stick binderless particleboard," Journal of Wood Science 66(1), 65. DOI: 10.1186/s10086-020-01913$\mathrm{Z}$

Onuorah, E. O. (2001). "The effects of some manufacturing variables on the properties of particleboard," Nigerian Journal of Technology 20(1), 19-40

Pereira, C., Carvalho, L. M. H., and Costa, C. A. V. (2006). "Modeling the continuous hot-pressing of MDF," Wood Science and Technology 40(4), 308-326. DOI: 10.1007/s00226-006-0067-8

Ramezanpoor Maraghi, M. M., Tabei, A., and Madanipoor, M. (2018). "Effect of board density, resin percentage and pressing temprature on particleboard properties made from mixing of poplar wood slab, citrus branches and twigs of beech," Wood Research 63(4), 669-682.

Saad, A., Kasim, A., Gunawarman, and Santosa, I. (2019). "Optimization of composition, temperature and time on production of particle board made from pine bark and EFB," in: IOP Conference Series: Earth and Environmental Science 327, article ID 012015. DOI: $10.1088 / 1755-1315 / 327 / 1 / 012015$

Taghiyari, H. R., Mobini, K., Samadi, Y. S., Doosti, Z., and Nouri, P. (2013). "Effects of 
nano-wollastonite on thermal conductivity coefficient of medium-density fiberboard," Journal of Nanomaterials \& Molecular Nanotechnology 02(01). DOI: 10.4172/23248777.1000106

Taghiyari, H. R., and Norton, J. (2014). "Effect of silver nanoparticles on hardness in medium-density fiberboard (MDF)," IForest, 8(October 2015), 677-680. DOI: 10.3832/ifor1188-007

Taghiyari, H. R., and Nouri, P. (2016). "Effects of nano-wollastonite on physical and mechanical properties of medium-density fiberboard," Maderas: Ciencia y Tecnologia 17(4), 833-842. DOI: 10.4067/S0718-221X2015005000072

Taş, H. H., and Sevinçli, Y. (2015). "Properties of particleboard produced from red pine (Pinus brutia) chips and lavender stems," BioResources 10(4), 7865-7876. DOI: 10.15376/biores.10.4.7865-7876

Thoemen, H., and Humphrey, P. E. (2003). "Modeling the continuous pressing process for wood-based composites," Wood and Fiber Science 35(3), 456-468.

Warmbier, K., Wilczyński, M., and Danecki, L. (2014). "Effects of some manufacturing parameters on mechanical properties of particleboards with the core layer made from willow Salix viminalis," Annals of Warsaw University of Life Sciences - SGGW Forestry and Wood Technology 88, 277-281.

Widyorini, R. (2020). "Evaluation of physical and mechanical properties of particleboard made from petung bamboo using sucrose-based adhesive," BioResources 15(3), 5072-5086. DOI: 10.15376/biores.15.3.5072-5086

Yel, H., Cavdar, A.D., and Torun, S.B. (2020). "Effect of press temperature on some properties of cement bonded particleboard," Maderas: Ciencia y Tecnologia 22(1), 83-92. DOI: 10.4067/S0718-221X2020005000108

Yildirim, M., and Candan, Z. (2021). "Performance properties of particleboard panels modified with nanocellulose/boric acid," BioResources 16(1), 1875-1890. DOI: 10.15376/biores.16.1.1875-1890

Zhu, L., Wang, Z., Shao, X., and Liu, Y. (2018). "Prescribed performance control for MDF continuous hot pressing hydraulic system," International Journal of Modelling, Identification and Control 29(3), 185. DOI: 10.1504/ijmic.2018.10012296

Article submitted: September 14, 2021; Peer review completed: October 17, 2021; Revised version received: October 26, 2021; Accepted: October 28, 2021; Published: November 12, 2021.

DOI: 10.15376/biores.17.1.159-176 